\title{
ADOPTING DIGITAL TECHNOLOGY IN MIDWIFERY PRACTICE - EXPERIENCES AND PERSPECTIVES FROM SIX PROJECTS IN EIGHT COUNTRIES (2014 - 2016)
}

\author{
Lilia Perez-Chavolla PhD ${ }^{1}$, Véronique Inès Thouvenot PhD $^{1}$, Doina Schimpf MSc $^{1}$, Amélie Moritz MEng ${ }^{2}$ \\ ${ }^{1}$ Foundation Millennia2025 Women and Innovation, Namur, Walonnia, Belgium \\ ${ }^{2}$ Sanofi Espoir Foundation, Paris, France
}

\begin{abstract}
This paper describes the cases of six midwifery projects of the Women Observatory for eHealth at the Millennia2025 Women and Innovation Foundation, to support the adoption of information and communication technologies (ICTs) in midwifery practice in eight countries from 2014 to 2016. The WeObservatory is a digital inclusion incubator aimed at reducing maternal and neonatal mortality in countries with limited resources by strengthening midwifery practice through the access to ICTs and eHealth applications. This paper describes how the collaboration with the WeObservatory supported these projects in the development and adoption of digital solutions for midwifery practice. It examines responses from the project leaders to an online survey conducted by the WeObservatory in January of 2018. Their responses provide insights on opportunities and challenges faced by these projects that can inform future midwifery eHealth projects. Building capacity among midwives for the adoption of digital competencies will help improve the quality of healthcare provided to mothers and their newborn babies in low-income countries.
\end{abstract}

Keywords: eHealth; midwifery; maternal health; ICT applications; mobile health

Perez-Chavolla, et al. JISfTeH 2019;7:e2(1-8).

DOI: https://doi.org/10.29086/JISfTeH.7.e2

Copyright:@ The Authors 2018

Open access, published under Creative Commons Attribution 4.0 BY International Licence

\section{Introduction}

In 2013, the Millennia2025 Women and Innovation Foundation, in partnership with the Sanofi Espoir Foundation, launched the Women Observatory for eHealth (WeObservatory), with the collaboration of Connecting Nurses, Connecting Midwives, and UniversalDoctor. ${ }^{1}$ The two foundations agreed to collaborate to promote bottom-up innovation in midwifery projects.

From 2014 to 2016, two midwifery projects were selected each year to join the WeObservatory. (Table 1) The selected projects — submitted by midwives from Africa, Asia and America through the Care Challenge participatory platform - were recognised with Midwives for Life Awards of the Sanofi Espoir Foundation. ${ }^{2}$ The collaboration with the WeObservatory gave these projects: (1) access to technical and financial support to develop new digital solutions for midwives; (2) the opportunity to expand their international visibility and recognition through scientific publications, participation in and presentations at international conferences, and (3) a gateway to network with other midwives and health professionals, sharing resources and expertise to improve maternal and neonatal health in their communities.

\section{Methods}

In January 2018, the WeObservatory invited the leaders of the five implemented midwifery projects to participate in an open-ended survey covering: key achievements, challenges and expansion plans for their projects, the contribution of the WeObservatory to their projects, and the impact of adopting ICT for midwifery practice.

Survey answers were grouped around four emerging themes: 1) supporting capacity building for midwives; 2) facilitating midwifery practice and improving maternal health through the adoption of mHealth applications; 3) increasing recognition of the role of midwives in healthcare; and 4) enabling collaborations. The article describes each of the projects as they relate to these themes. It then discusses challenges faced by the projects and how the collaboration with the WeObservatory helped overcome them.

\section{Results}

Supporting Capacity Building for Midwives - Projects from Mexico, Netherlands-Morocco, and Ethiopia

ICTs are considered powerful tools for strengthening health systems; they facilitate capacity building among health 
Table 1. eHealth projects participating in the WeObservatory $(2014-2016)$, in chronological order.

\begin{tabular}{|c|c|c|c|}
\hline Organisation & Project & Target Population & Digital Solutions Delivered under the WeObservatory \\
\hline $\begin{array}{l}\text { Centre for the } \\
\text { Adolescents of } \\
\text { San Miguel de } \\
\text { Allende (CASA), } \\
\text { Mexico }\end{array}$ & $\begin{array}{l}\text { ICTs for } \\
\text { Midwives }\end{array}$ & $\begin{array}{l}\text { Professional } \\
\text { midwives, nurses and } \\
\text { physicians providing } \\
\text { maternal and } \\
\text { neonatal care to } \\
\text { expectant women in } \\
\text { rural areas of } \\
\text { Mexico. }\end{array}$ & $\begin{array}{l}\text { - Online training course on the use of ICT applications for } \\
\text { midwifery, composed of eight } 20 \text {-minute modules. } \\
\text { - eBook in Spanish expanding the content of the original } \\
\text { online course's ICT modules. } \\
\text { - } 100 \text { USB keys with a copy of the eBook for offline } \\
\text { access. }\end{array}$ \\
\hline $\begin{array}{l}\text { Association } \\
\text { PanMilar, } \\
\text { Switzerland }\end{array}$ & $\begin{array}{l}\text { Multilingual } \\
\text { Interpretation } \\
\text { for Pregnant } \\
\text { Migrant } \\
\text { Women }\end{array}$ & $\begin{array}{l}\text { Pregnant migrant } \\
\text { women living in the } \\
\text { Swiss Canton of } \\
\text { Vaud. }\end{array}$ & $\begin{array}{l}\text { - New PanMilar website. } \\
\text { - New animation video explaining to pregnant migrant } \\
\text { women where and how to find prenatal courses, } \\
\text { midwives and interpreters in more than } 50 \text { languages. } \\
\text { - UniversalWomen Speaker and Refugee Speaker - Mobile } \\
\text { and web tools providing medical translations during } \\
\text { pregnancy, childbirth and overall maternal health } \\
\text { issues to facilitate multilingual communication between } \\
\text { women and healthcare professionals not sharing a } \\
\text { common language. }\end{array}$ \\
\hline $\begin{array}{l}\text { Royal Dutch } \\
\text { Organization of } \\
\text { Midwives } \\
\text { (KNOV), } \\
\text { Netherlands }\end{array}$ & $\begin{array}{l}\text { Twin2Win, } \\
(\mathrm{t} 2 \mathrm{t})\end{array}$ & $\begin{array}{l}\text { Midwives of } \\
\text { Netherlands with } \\
\text { midwives in Sierra } \\
\text { Leone and Morocco. }\end{array}$ & $\begin{array}{l}\text { Twin2Win - A mobile application to foster the twinning } \\
\text { methodology, collaboration and experience-sharing } \\
\text { among midwives from different cultures. }\end{array}$ \\
\hline $\begin{array}{l}\text { Japanese } \\
\text { Midwives } \\
\text { Association } \\
\text { (JMA), Japan, } \\
\text { and Mongolian } \\
\text { Midwives } \\
\text { Association } \\
\text { (MMA), } \\
\text { Mongolia }\end{array}$ & $\begin{array}{l}\text { Midwives } \\
\text { Reducing } \\
\text { Obesity in } \\
\text { Mongolia }\end{array}$ & $\begin{array}{l}\text { Midwives and } \\
\text { expectant mothers in } \\
\text { Mongolia. }\end{array}$ & $\begin{array}{l}\text { Happy Baby, Happy Mom - A mobile application to } \\
\text { promote the reduction of obesity among pregnant } \\
\text { women. Japanese midwives twinned with Mongolian } \\
\text { midwives to share experiences and address problems of } \\
\text { maternal and neonatal mortality caused by obesity } \\
\text { among pregnant women in Mongolia. }\end{array}$ \\
\hline $\begin{array}{l}\text { Photographers } \\
\text { Miriam Ackroyd, } \\
\text { Australia and } \\
\text { Doina Schimpf, } \\
\text { Moldova }\end{array}$ & $\begin{array}{l}\text { Portrait of a } \\
\text { Midwife }\end{array}$ & $\begin{array}{l}\text { Midwives in } \\
\text { Australia, } \\
\text { Bangladesh and } \\
\text { Moldova. }\end{array}$ & $\begin{array}{l}\text { - } 139 \text { photo portraits illustrating the daily work and lives } \\
\text { of midwives and young students attending pregnant } \\
\text { mothers in Asia and Europe. }\end{array}$ \\
\hline $\begin{array}{l}\text { Hospital of } \\
\text { Gondar, Gondar, } \\
\text { Ethiopia }\end{array}$ & $\begin{array}{l}\text { Training } \\
\text { Midwives on } \\
\text { Emergency } \\
\text { Obstetrics }\end{array}$ & $\begin{array}{l}\text { Midwives in Gondar, } \\
\text { Ethiopia. }\end{array}$ & $\begin{array}{l}\text { - This project completed the preparation phase after one } \\
\text { year of work. } 20 \text { midwives, } 4 \text { trainers and learning } \\
\text { materials were ready for the implementation phase. The } \\
\text { implementation was not operational due to } \\
\text { communication and financial limitations. }\end{array}$ \\
\hline
\end{tabular}

workers in rural and low-income environments and promote equal access to care. ${ }^{3-6}$ Three of the six WeObservatory projects focused on building capacity among midwives:

ICTs for Midwives - Centre for the Adolescents of San Miguel de Allende (CASA), Mexico

In 2014, CASA developed the eLearning programme, ICTs for Midwives, with the support of an interdisciplinary international team convened by the WeObservatory. The blended learning programme promotes digital competency among CASA's midwifery students by introducing them to the use of an eLearning platform, highlighting electronic resources to support evidence-based practice, and familiarising them with the use of eHealth and mHealth applications and telemedicine for maternal and neonatal health.

The course was launched as a pilot programme in Spanish in $2014,{ }^{7}$ and uploaded into CASA's eLearning platform ${ }^{8}$ and the WeObservatory Academy a year later, after obtaining 
feedback from pilot programme students. To open access to the course's ICT-related content beyond CASA's platform, the WeObservatory published in 2016 the eBook Aplicaciones Digitales para la Salud Materna e Infantil, providing CASA a hundred USB keys with copies of the eBook so that students can access the material offline. (Figure 1)

Twin2Twin (t2t) - Royal Dutch Organisation of Midwives (KNOV), Netherlands

With technical support and eHealth expertise from the WeObservatory, Twin2Twin developed the mobile application Twin2win, which facilitates interactions and the exchange of experiences between "twinned" midwives. Twinning was originally developed by the International Confederation of Midwives (ICM) as a method to promote cooperation between two midwifery associations through the exchange of best practices. According to ICM, by building skills and relationships, twinning improves organisational effectiveness and enables networking and solidarity. ${ }^{9}$ Twin2Twin adapted the twinning methodology to interpersonal relationships, ${ }^{10}$ providing in the Twin 2 win mobile application a platform for midwives in different countries to build sustainable relationships and promote cross-cultural collaboration to achieve joint goals. Building on this international collaboration, the application's content and design were enriched by twinning experiences with midwives in the Netherlands, Sierra Leone and Morocco. Available in English and French, Twin2win includes a library on the Twinning method, and sections for project teams and twins. (Figure 2)

Training Midwives on Obstetrical Emergencies - Hospital of Gondar, Ethiopia

This project did not reach the implementation phase, but it aimed at improving the technical skills of midwives working in peripheral health centres around Gondar, Ethiopia. With financial support from the WeObservatory and the Nursing Education Partnership Initiative (NEPI) of Columbia Uni-

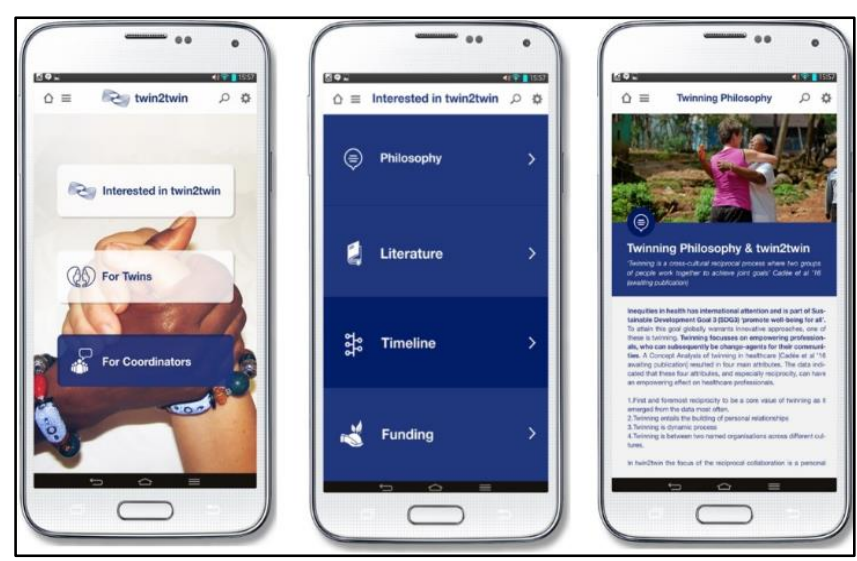

Figure 2. Twin2Win mobile application (Source: http://www.m2025-weobservatory.org/twin2twin.html).

versity, and in collaboration with the Department of Midwifery of the University of Gondar, twenty midwives would receive an intensive 18 days live-training on Basic Essential Obstetric and Newborn Care (BeMONC), a national training manual developed by the Ethiopian Ministry of Health in 2013. The ICT component of this project was limited to publishing a digital version of the manual, which would be made available online for ease of access.

In the survey, participants emphasised the importance of developing digital skills among midwives. The use of an eLearning platform like CASA's enabled individualised learning and interdisciplinary exchanges between midwives, nurses, and doctors. CASA's eLearning platform has proven an effective tool for midwives to "learn in a non-threatening manner about evidence-based medicine and the benefits of the midwifery model of care". Similarly, the Twin2win application is being used "as the basic knowledge for midwives to start a twinning project".

The respondents highlighted the effectiveness of

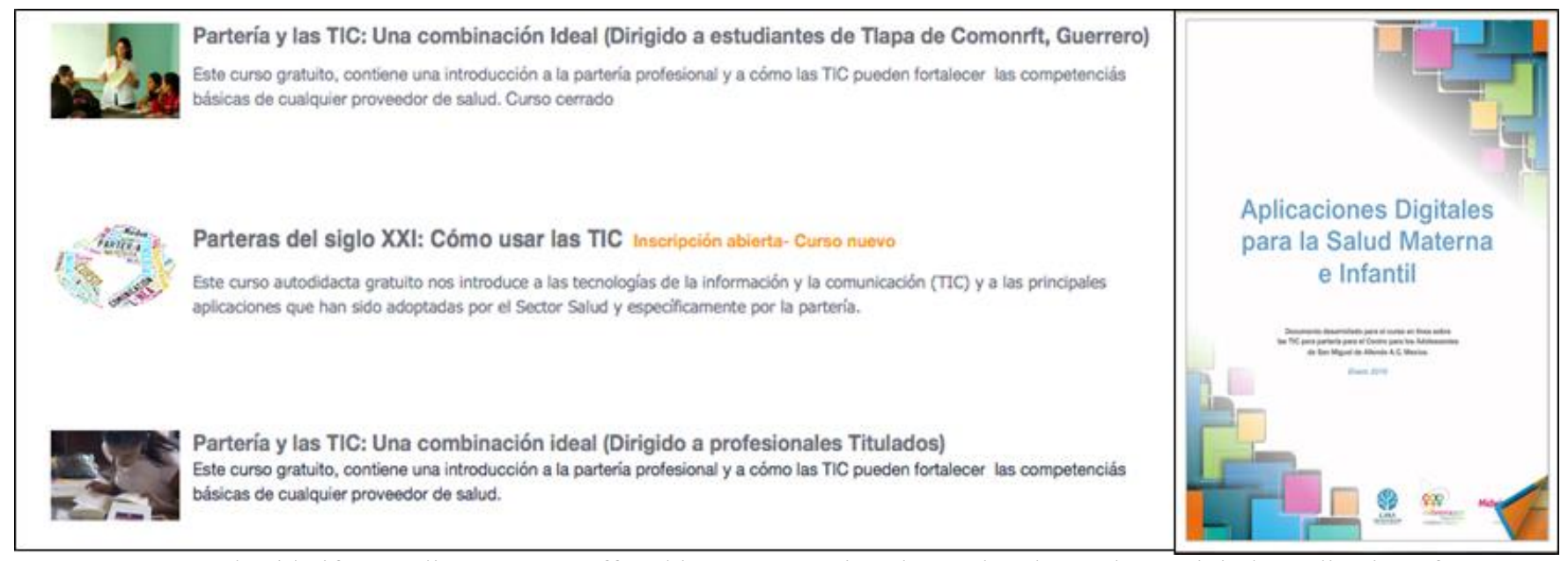

Figure 1. ICT and Midwifery Online Courses offered in CASA's Virtual Portal and eBook on Digital Applications for Maternal and Infant Health (Source: http://casa.org.mx/campus-virtual/). 
integrating eLearning into midwifery and medical school curricula to improve digital competency, facilitate professional development, and build confidence among midwives to defend their profession and care for their patients. They noted that mobile applications made information easily accessible to midwives, particularly to those from the digital generation.

Improving Midwives' Interaction with Expectant Mothers Projects from Switzerland and Mongolia-Japan

Communication and cultural competence are essential skills that impact the quality of service midwives and other healthcare workers provide to expectant mothers. Two WeObservatory projects focused on developing digital tools that facilitate sharing prenatal information with expectant mothers from different cultural backgrounds, making cultural competence indispensable.

Multilingual Interpretation for Pregnant Migrant Women Association PanMilar, Switzerland

Midwives in Association PanMilar provide pregnancy advice and perinatal preparation classes in native languages to pregnant migrant women living in the canton of Vaud, Switzerland, who do not speak French and lack family support. Experienced intercultural translators help midwives engage moms-to-be in conversation about perinatal topics and conduct practical exercises that take into consideration their migratory, linguistic and cultural background. Thanks to the interpreters, moms-to-be can share in their native languages birth-giving traditions from their home countries and/or their personal experiences giving birth, while learning what to expect as a mother living in Switzerland. ${ }^{11}$

To improve the women's access to prenatal services, PanMilar designed paper brochures in 25 languages with the support of the Public Health Department of Vaud. Yet, patients preferred accessing health information digitally. Responding to this feedback, PanMilar, in collaboration with the WeObservatory, produced a short video to substitute the brochures, and in 2016, launched a new website that provides information in 39 languages on services and activities available to pregnant women. (Figure 3)

Since 2016, 190 women have registered for the courses using this website and, according to the project leaders, the website has become an essential informational tool for both migrant women and midwives. As of March of 2018, the website had registered more than 2,900 visits from 42 countries via computers (63\%), smartphones (31\%) and tablets (5\%). In partnership with UniversalDoctor, the WeObservatory also developed two mobile applications, UniversalWomen Speaker and Refugee Speaker, available for mobiles, tablets and computers, to allow doctors and midwives to communicate with their patients in more than 17 languages, using written translations and audio in native languages. (Figure 4)

Midwives Reducing Obesity in Mongolia - JMA and MMA, Japan and Mongolia

This twinning project between the Japanese Midwives Association (JMA) and the Mongolian Midwives Association (MMA) uses mobile phones to inform women in Mongolia of the increased health risks associated with obesity during pregnancy. With the support of the WeObservatory and Universal Doctor, the project developed and launched, in 2016, the mobile application Happy Baby, Happy Mom, so that more women across the country could have access to this information. (Figure 5)

The application uses attractive visuals, graphics, tables and animation to share information adapted from pamphlets originally designed by the midwives and distributed to

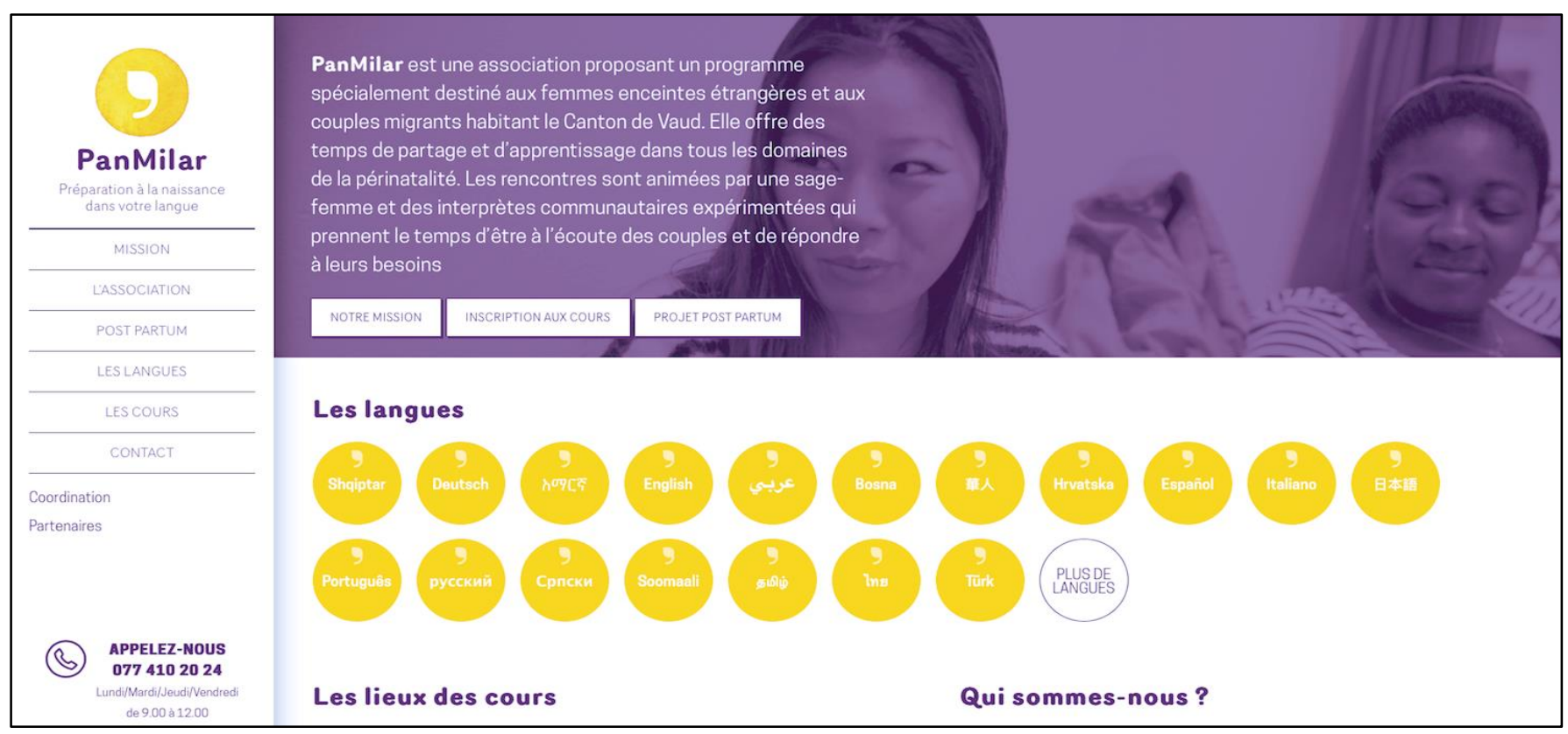

Figure 3. PanMilar's new website showing the multiple languages courses are available in. (Source: https://www.panmilar.ch). 


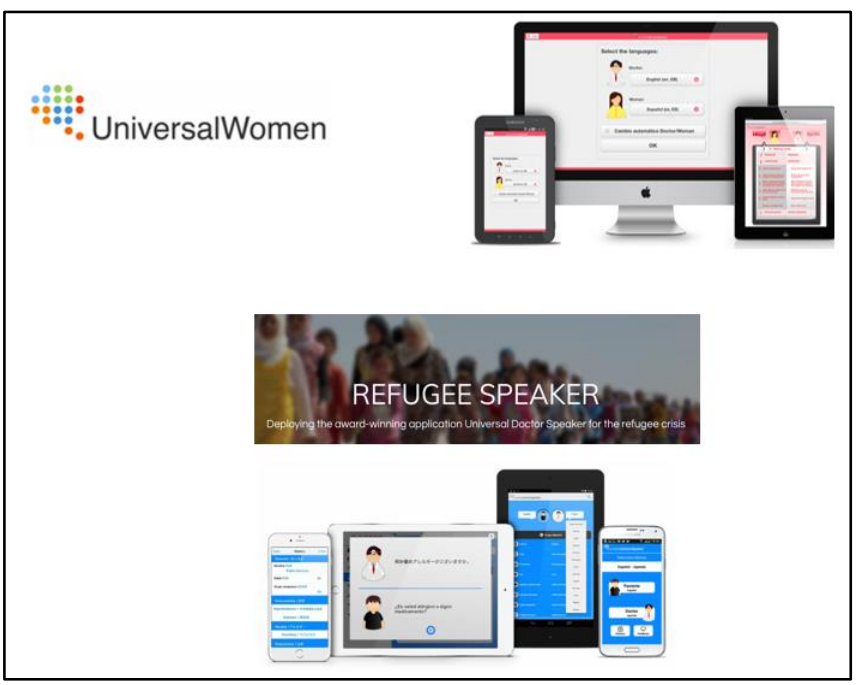

Figure 4. Universal Women Speaker and Refugee Speaker (Source: http://www.u-women.com/ http://www.refugeespeaker.org).

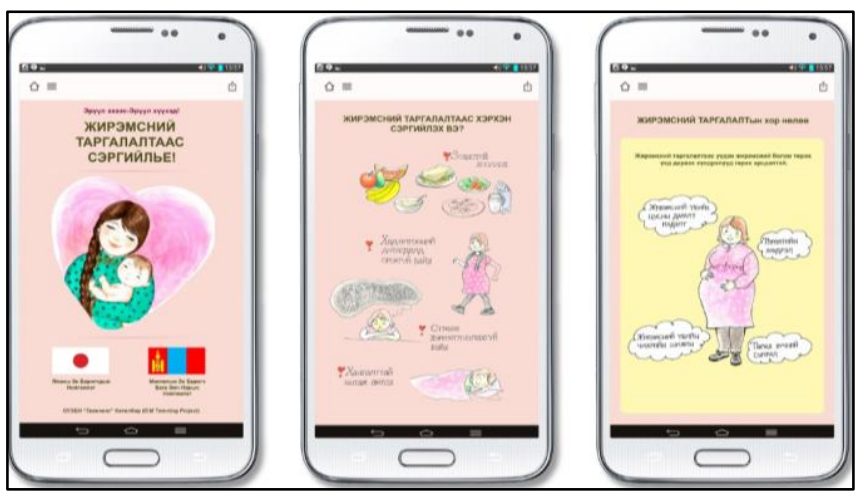

Figure 5. Happy Baby, Happy Mom application in Mongolian and English (Source: http://www.m2025weobservatory.org/midwives-reducing-obesity-inmongolia.html)

82,000 women in Mongolia. JMA and MMA report that the application is already being used in Ulaanbaatar and in rural areas of the country. At the request of midwives in Mongolia, JMA funded the development of the app version for Apple phones, and to reach an international audience, the app was made available in English in 2018.

The development of the mobile application enabled the project's participants to learn its usefulness for improving "the effectiveness of the midwife-patient dynamic". Midwives and mothers in Mongolia appreciate having access to an application in their own language that is easy to use and understand, and that teaches them how to calculate their body mass index.

Raising Awareness of the Importance of Midwifery Practice-Project from Australia

Portrait of a Midwife, Australia

This project documents midwifery practice through photo portraits to raise awareness of the importance of and need for skilled midwives. The portraits capture field experiences and challenges of midwifery activities in diverse communities for their dissemination in international networks and media. In 2016, photographers Miriam Ackroyd and Doina Schimpf took 139 photos illustrating the daily work and lives of midwives and young students attending expectant women at midwifery schools and hospitals in Bangladesh and Moldova. ${ }^{12}$ (Figure 6) A set of photos was exhibited at the 31 ICM Triennial Congress, at the stand of the Sanofi Espoir Foundation. ${ }^{13}$

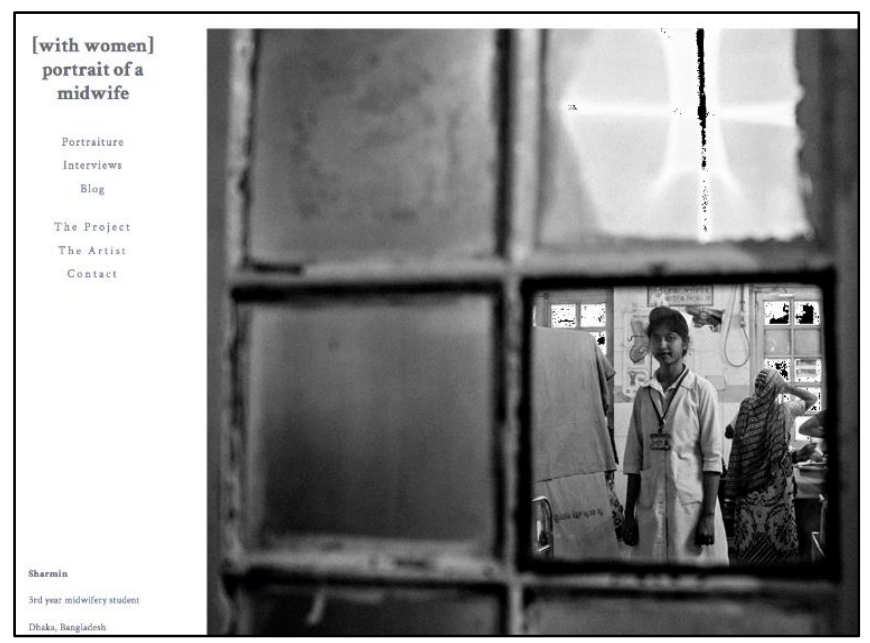

Figure 6. Portrait of a Midwife website (Source: http://www.portraitofamidwife.com).

The project leader noted that "It does not matter what language is being spoken, the heart and actions of midwives are the same: To be with women". For her, photography is an instrument for education and change; "images can inform, teach, inspire, agitate and shake us to the core", she noted.

In countries where professional midwifery is not well known, it becomes essential to raise awareness of their work and their capacity. CASA's project leader noted that fostering digital literacy among midwives has facilitated the recognition of their vital role by other healthcare professionals. Since the launch of its eLearning course, CASA has worked with universities and state health offices to promote the integration of midwifery formation in university curricula and of ICT training in professional midwifery schools. Thanks to these efforts, the Secretariat of Health in the state of Veracruz made CASA's midwifery online course mandatory for all healthcare providers working in the state's 500 public hospitals and clinics. The online training has also been approved for its distribution through the World Health Organization's Pan-American Health virtual campus, managed by the Mexican Secretariat of Health.

\section{Enabling Collaborations}

Enabling collaborations is a key purpose of the WeObservatory. Their participation in the WeObservatory helped projects increase their international exposure, allowing midwives to share their knowledge, expertise and 
practices in international and scientific arenas, and strengthening connections between them. The projects were presented in 50 international conferences in English, Spanish or French, and information on their projects was shared through brochures, bookmarks, flyers, as well as social media. The WeObservatory Blog includes 109 news items covering topics in 35 categories, six interviews of women influencers in eHealth, 10 videos and 210 photos relating to the projects. ${ }^{14}$ The visibility of WeObservatory Projects is listed in Table 2.

Table 2. Expanded Visibility of WeObservatory Projects

\begin{tabular}{|l|l|}
\hline Project & International Visibility \\
ICTs for & $\begin{array}{l}\text { CASA, the eBook, and the online training } \\
\text { were represented at six conferences, } \\
\text { including MEDETEL in } 2015^{15} \text { and 2016. }\end{array}$ \\
\hline \multirow{3}{*}{ PanMilar } & $\begin{array}{l}\text { The project was presented at local events or } \\
\text { meetings in Geneva and Lausanne, } \\
\text { including the Giving Women Annual } \\
\text { Conference in Geneva in 2016. }\end{array}$ \\
\hline \multirow{5}{*}{ Twin2Win } & $\begin{array}{l}\text { Demo version (v1.0) of the mobile app was } \\
\text { presented at the Global Forum, in } \\
\text { Eindhoven in 2016, during the } \\
\text { WeObservatory's session on "Digital } \\
\text { Communities", and at the ICM Congress } \\
2017 .{ }^{17}\end{array}$ \\
\hline Mongolia & $\begin{array}{l}\text { The mobile application was presented at } \\
\text { international conferences in } 2017 .{ }^{17}\end{array}$ \\
\hline \multirow{3}{*}{ Portraits of } \\
Midwives & $\begin{array}{l}\text { A selection of photos and quotes was } \\
\text { showcased at events and conferences, } \\
\text { including the ICM Congress in Toronto in } \\
2017 .{ }^{17}\end{array}$ \\
\hline
\end{tabular}

\section{Discussion}

Innovation, capacity building, communication and collaboration are core principles of the WeObservatory that informed its collaboration with the selected projects. In terms of innovation, the collaboration of the WeObservatory contributed to the development of four mobile applications Twin2Win, UniversalWomen Speaker, Refugee Speaker, and Happy Mom, Happy Baby-adapted to local languages and needs. These applications facilitated collaboration and information sharing between midwives in different countries and with patients from different backgrounds.

This collaboration also improved access to education and eLearning opportunities for midwives and pregnant women through the development of online training platforms, publications, videos, portraits and websites, raising awareness of the importance of midwifery practice for maternal health.

Like many other eHealth projects being implemented worldwide, the WeObservatory projects had to overcome infrastructural and technical barriers, scarce financial and human resources, and cultural differences. Access to CASA's eLearning platform has been affected by differences in the quality and speed of broadband services available throughout the country. To partially overcome this barrier, the WeObservatory distributed USB keys with some of the course material. Similarly, PanMilar midwives faced the challenge of having to learn about digital communication to develop their informational video. To this end, the WeObservatory provided technical advice on visuals and animations to make the video easily understandable.

The Twin2Win project faced cultural differences in terms of work, life and communication styles of twinned midwives in Netherlands and Morocco. The mobile application financed by the WeObservatory aimed at improving communication. Similarly, the Happy Baby, Happy Mom app had to overcome the technical challenge of integrating the specificities of Mongolian language into the app, as well as cultural differences. The project manager noted that the professionalism and enthusiasm of the midwives made up for these obstacles. Developing the mobile app brought Mongolian and Japanese midwives participating in the twinning project closer together and strengthened their cooperation.

Finally, the Ethiopian project highlights the importance of institutional support in successful project implementation. One year into the collaboration, the course schedule had been developed, the training budget was approved, and the midwives and trainers had been selected. But NEPI had not officially confirmed to the Department of Midwifery of the University of Gondar its participation in and financial support of the programme, creating uncertainty regarding the feasibility, quality and impact of the training. These factors, combined with changes in key project personnel in Ethiopia, prompted the WeObservatory and the Sanofi Espoir Foundation to cancel their participation.

In sum, the support of the WeObservatory, with both financial and technical expertise, contributed for the projects to advance their goals. Project leaders highlighted the added value that adopting mobile applications and digital technologies provided to their projects by allowing midwives to access information and keep in touch with their patients and with each other. The ubiquity of mobile phones makes this an easily accessible and adequate medium to engage and educate young midwives.

Driven by the results achieved by the WeObservatory projects so far, the Millennia2025 Women and Innovation Foundation and Sanofi Espoir Foundation extended their collaboration for the 2017 - 2018 period to continue facilitating better pregnancy monitoring and quality of healthcare through innovative projects for midwives and women. To promote visibility, the projects were encouraged to participate in the call for submissions from the Journal of the International Society for Telemedicine and eHealth for the third Special Issue on Women in eHealth in 2019. 


\section{Conclusion}

The 2014-2016 WeObservatory projects discussed here are selected eHealth and mHealth case studies that, despite their early stages of implementation, are already making an impact on midwifery practice and the health of the women and babies they serve. Five of the six selected projects expanded their reach and visibility thanks to their collaboration with the Millennia2025 Foundation and Connecting Midwives partnership. The WeObservatory provided midwives a platform to help the projects grow and supported the recognition of midwives' daily work at international levels.

\section{Corresponding author:}

Veronique Thouvenot

Foundation Millennia2025 Women and Innovation

9/4, avenue Louis Huart

B 5000 Namur

Wallonia (Belgium)

eMail: thouvenot.veronique@millennia2025-foundation.org

Conflict of interest. The authors declare no conflicts of interest.

Acknowledgments. The authors would like to thank the Sanofi Espoir Foundation and the WeObservatory of the Millennia2025 Foundation for the funds provided to conduct the survey and analyse the qualitative data used for this article.

\section{References}

1. The Foundation Millennia2025 Women and Innovation. An Action Plan for Women's Empowerment and gender equality. Available at: http://www.millennia2025-

foundation.org/index_en.html accessed 30 September 2018.

2. Connecting Midwives. Midwives for Life Awards. 2013. Available at: http://connectingmidwives.com/web/projects_awards accessed 30 September 2018.

3. Bagayokoa CO, Anneb A, Fieschi M, Geissbuhler A. Can ICTs Contribute to the Efficiency and Provide Equitable Access to the Health Care System in SubSaharan Africa? The Mali Experience. Yearb Med Inform 2011:20(1):33-38. DOI: 10.1055/s-00381638734

4. Mars M. Building the capacity to build capacity in ehealth in sub-Saharan Africa: the KwaZulu-Natal experience. Telemed J E Health 2012;18(1):32-37. https://doi.org/10.1089/tmj.2011.0146

5. Curran VR, Fleet L, Kirby F. Factors influencing rural health care professionals' access to continuing professional education. Aust J Rural Health 2006:14(2):51-55. https://doi.org/10.1111/j.14401584.2006.00763.x

6. Bagayoko CO, Perrin C, Gagnon MP, et al. Continuing distance education: a capacity-building tool for the deisolation of care professionals and researchers. $J$ Gen Intern Med 2013;28(Suppl 3):666-670. https://doi.org/10.1007/s11606-013-2522-1

7. The Women Observatory for eHealth, WeObservatory. 2015. An online course on ICTs for Midwifery.

Available at: http://www.m2025weobservatory.org/icts-for-midwives.html accessed 30 September 2018.

8. CASA. Parteras del Siglo XXI. 2018. Como Usar las TIC. Campus Virtual. Available at: http://casa.org.mx/lms/index.php accessed 4 November 2018.

9. International Confederation of Midwives (ICM). Twinning Programmes. Available at: http://internationalmidwives.org/projectsprogrammes/former-projects/icm-interventions/moretwinning-programmes.html accessed on May 5, 2018.

10. Cadée F, Nieuwenhuijze MJ, Lagro-Janssen AL, De Vries R. The state of the art of twinning, a concept analysis of twinning in healthcare. Global Health 2016;12(1):66. https://doi.org/10.1186/s12992-016$\underline{0205-5}$

11. PanMilar. 2015. Des cours de preparation a la naissance pour femmes migrantes, avec interprétariat communautaire. Available at: http://www.m2025weobservatory.org/sage-femmes-et-femmesmigrantes.html accessed 30 September 2018.

12. Portrait of a midwife. Portraits of midwives in Bangladesh. 2016. Available at http://www.m2025weobservatory.org/portrait-of-a-midwife.html accessed 30 September 2018.

13. International Confederation of Midwives (ICM). Toronto 2017: 31st ICM Triennial Congress. Available at: https://internationalmidwives.org/events/triennialcongress/toronto-2017 accessed 30 September 2018.

14. The Blog of the Women Observatory for eHealth. Available at: http://weobservatory.com/ accessed 30 September 2018.

15. Thouvenot, V, Perez-Chavolla, L. 2015. Report of the Special Session on Women 2015: Empowering Women in eHealth and Telemedicine through Education. Luxemburg, Medetel Conference, April 2224, 2015. Available at: http://www.millennia2015.org/files/files/M25_WeObs _Projets/Events/Report_of the_Women_session_mede tel_2015.pdf accessed on May 5, 2018.

16. The Women Observatory for eHealth. 2016 Events. 2016. Available at: http://www.m2025weobservatory.org/2016.html accessed 30 September 2018. 
17. The Women Observatory for eHealth. 2017 Events.

2017. Available at: http://www.m2025-

weobservatory.org/2017.html accessed 30 September 2018. 